\title{
Käyttävätkö vasikat karjaharjaa?
}

Leena Tuomisto $^{1)}$, Katja Naumanen ${ }^{2)}$, Arto Huuskonen ${ }^{3)}$ ja Jaakko Mononen ${ }^{1,4)}$

${ }^{1)}$ Maa- ja elintarviketalouden tutkimuskeskus, Kotieläintuotannon tutkimus, Halolantie 31 A, 71750

Maaninka,leena.tuomisto@mtt.fi, jaakko.mononen@mtt.fi

${ }^{2)}$ Itä-Suomen yliopisto, Biologian laitos, PL 111,80101 Joensuu, kanauman@student.uef.fi

${ }^{3)}$ Maa- ja elintarviketalouden tutkimuskeskus, Kotieläintuotannon tutkimus, Tutkimusasemantie 15, 92400 Ruukki, arto.huuskonen@mtt.fi

${ }^{4)}$ Itä-Suomen yliopisto, Biotieteiden laitos, PL 1627, 70211 Kuopio, jaakko.mononen@uef.fi

\section{Tiivistelmä}

Turkinhoito on tärkeä osa nautojen luonnollista käyttäytymistä. Karjaharjoja on kuitenkin tavallisesti vain lehmien ja hiehojen käytössä. Edulliset ja vähän tilaa vievät kiinteät karjaharjat voisivat olla järkevä vaihtoehto vasikoille. Tutkimuksen tavoitteena oli selvittää, hyödyntävätkö vasikat kiinteää karjaharjaa turkin hoitamisessa sekä onko vasikoiden turkinhoitokäyttäytymisessä eroa, kun eläimillä on mahdollisuus käyttää karjaharjaa ja kun mahdollisuutta ei ole. Kokeessa oli yhteensä 19 ayrshire- ja holstein-friisiläis-rotuista sonnivasikkaa. Vasikat kasvatettiin viiden eläimen ryhmissä ryhmäkarsinoissa lämpimässä navetassa. Kiinteät karjaharjat (1 harja/karsina, harjan koko $10 \times 50 \mathrm{~cm}$, nylonharjasten pituus $6 \mathrm{~cm}$ ja halkaisija $3 \mathrm{~mm}$ ) kiinnitettiin karsinoiden etuseiniin eläinten korkeudelle. Vasikat saivat nurmisäilörehua vapaasti ja väkirehua enintään $3 \mathrm{~kg} / \mathrm{eläin/päivä.} \mathrm{Kokeen} \mathrm{alkaessa} \mathrm{vasikat} \mathrm{olivat}$ keskimäärin 17 viikon ikäisiä ja $139 \mathrm{~kg}$ painoisia. Kokeessa oli kaksi 20 vrk pituista jaksoa. Molempien jaksojen ensimmäisen 10 vrk aikana vasikoilla ei ollut käytössään karjaharjaa (EIKAR) ja jaksojen jälkimmäisen 10 vrk aikana vasikoilla oli käytössään karjaharja (KAR). Vasikoita videokuvattiin neljä kertaa 15 tunnin (klo 6:00-21:00) ajan. Videokuvaukset tehtiin jokaisen harjattoman ja harjallisen jakson viimeisen kolmen vuorokauden aikana. Videonauhoilta kerättiin vasikoiden turkinhoitoon liittyvät käyttäytymishavainnot jatkuvalla seurannalla. Kaikki vasikat hyödynsivät karjaharjaa hankaamiseen. Karjaharja ei vaikuttanut vasikoiden turkin hoitoon (nuolee itseään, hankaa, rapsuttaa sorkalla) kaikkiaan käyttämään aikaan (keskimäärin $24 \mathrm{~min}$ ), mutta eri turkinhoitotoimintojen suhteelliset osuudet muuttuivat, kun vasikoilla oli käytössään karjaharja. Vasikat nuolivat jalkojaan merkitsevästi vähemmän (11 vs. 14 min, $P=0,022)$ ja keskivartaloaan suuntaa antavasti vähemmän (6 vs. 7 min, $\mathrm{P}=0,068)$ KAR-käsittelyllä kuin EIKAR-käsittelyllä. Rakenteita vasten hankaamista $(0,2$ vs. 1,3 min, $\mathrm{P}<0,001)$ sekä toista eläintä vasten hankaamista (vain jaksolla $2 ; 0,02$ vs. $0,30 \mathrm{~min}, \mathrm{P}=0,002$ ) havaittiin vähemmän KAR-käsittelyllä kuin EIKAR-käsittelyllä. Kaikkiaan hankaamiseen käytetty aika oli kuitenkin suurempi $(\mathrm{P}<0,001)$ KAR-käsittelyllä $(5 \mathrm{~min})$ kuin EIKAR-käsittelyllä $(2 \mathrm{~min})$, mikä oli seurausta karjaharjan käytöstä. Vasikat syrjäyttivät toisiaan karjaharjalta keskimäärin 0,2 kertaa/vasikka 15 tunnin tarkkailun aikana. Saadessaan kiinteän karjaharjan käyttöönsä vasikat nuolivat erityisesti jalkojaan vähemmän ja vastaavasti hankasivat itseään enemmän. Itsensä nuolemisen vähentyminen voi merkitä vasikoiden hyvinvoinnin parantumista, koska jatkuvaa ja usein toistuvaa itsensä nuolemista pidetään epänormaalina käyttäytymisenä. Karjaharjaan kohdistuva kilpailu oli hyvin vähäistä, kun yhtä karjaharjaa käytti viisi vasikkaa. Tutkimuksen perusteella kiinteää karjaharjaa, jonka etuna on myös edullisuus, voidaan suositella vasikoille.

Asiasanat: vasikat, karjaharjat, turkinhoitokäyttäytyminen, hyvinvointi 


\section{Johdanto}

Turkinhoito on tärkeä osa nautojen luonnollista käyttäytymistä. Turkinhoito edistää eläimen terveyttä helpottamalla lian, lannan, hyönteisten ja loisten irtoamista iholta ja karvapeitteeltä (Simonsen 1979). Naudat hoitavat karvapeitettään nuolemalla, rapsuttamalla sorkalla tai sarvilla sekä huiskimalla hännällään. Kehon alueita, joihin eläimen on vaikea ylettää, rapsutellaan tai hangataan ympäristön rakenteita vasten.

Karjaharjat on alun perin kehitetty lehmille helpottamaan turkin hoitoa intensiivisissä kasvatusoloissa. Pyörivä karjaharja aktivoituu eläimen tönäisystä tarjoten eläimelle vaivattoman tavan hoitaa turkkiaan. Lähes kaikki lehmät ja vasikat hyödyntävät pyörivää karjaharjaa saadessaan mahdollisuuden sen käyttöön (Georg ja Totschek 2001, DeVries ym. 2007, Georg ym. 2007). Kiinteät karjaharjat koostuvat yhdestä tai useammasta harjasta, joita vasten eläimet voivat hangata itseään. Karjaharjan käyttöä on tutkittu lehmillä jonkin verran (Georg ja Totschek 2001, DeVries ym. 2007), mutta vasikoiden turkinhoitokäyttäytymisestä tiedetään vähemmän (Georg ym. 2007, Ninomiya ja Sato 2009). Pyörivät karjaharjat ovat arvokkaita ja vievät tilaa, minkä vuoksi niitä hankitaan lähinnä vain lehmien ja hiehojen käyttöön. Vasikoilla ei useinkaan ole käytössään minkäänlaisia karjaharjoja. Edulliset ja vähän tilaa vievät kiinteät karjaharjat voisivat olla järkevä vaihtoehto vasikkatiloihin.

Tutkimuksen tavoitteena oli selvittää, hyödyntävätkö vasikat kiinteää karjaharjaa turkin hoitamisessa sekä onko vasikoiden turkinhoitokäyttäytymisessä eroa, kun eläimillä on mahdollisuus käyttää karjaharjaa ja kun mahdollisuutta ei ole.

\section{Aineisto ja menetelmät}

Tutkimus tehtiin MTT Ruukin toimipaikassa keväällä 2009. Kokeessa käytettiin 19 maitorotuista sonnivasikkaa, joista 11 oli rodultaan ayrshirejä ja 8 holstein-friisiläisiä. Sonnivasikat hankittiin Ruukkiin ternivasikoina A-Tuottajien vasikkavälityksestä talvella 2009. Vasikat nupoutettiin 3-4 viikon ikäisinä. Vasikat kasvatettiin viiden eläimen ryhmäkarsinoissa lämpimässä navetassa. Ryhmäkarsinat olivat kooltaan $300 \times 350 \mathrm{~cm}$, joten tilaa oli vasikkaa kohden $2,1 \mathrm{~m}^{2}$. Karsinoiden lattiasta noin 3/4 oli kumimatolla päällystettyä betonia ja 1/4 metalliritilää. Karsinoissa käytettiin kuivikkeena pientä määrää turvetta. Karsinoiden väliseinät olivat kiinteää levyä. Karjaharjat (1 harja/karsina, harjan koko $10 \times 50$ $\mathrm{cm}$, nylonharjasten pituus $6 \mathrm{~cm}$ ja halkaisija $3 \mathrm{~mm}$ ) kiinnitettiin karsinoiden etuseiniin pystysuoraan noin $75 \mathrm{~cm}$ korkeudelle harjan keskipisteestä mitattuna. Kokeessa käytettiin lehmille tarkoitettuja harjoja, jotta ne olisivat varmasti turvallisia vasikoille.

Vasikat oli jaettu samanaikaista tuotantokoetta varten karsinoittain satunnaisesti kolmelle eri koeruokinnalle, jotka erosivat toisistaan väkirehun koostumuksen osalta. Ruokinnat olivat: 1) väkirehuna ohra, ei rypsilisää, kivennäislisä, 2) väkirehuna seos, jossa $80 \%$ ohraa ja $20 \%$ rypsitiivistettä, kivennäislisä, 3) väkirehuna teollinen täysrehu (Suomen Rehun Primo I). Väkirehun määrä rajoitettiin siten, että väkirehuannos oli enintään $3 \mathrm{~kg} / \mathrm{eläin} /$ päivä. Vasikat saivat kokeen ajan vapaasti nurmisäilörehua. Erilaisten väkirehuruokintojen ei katsottu vaikuttavan käyttäytymistutkimuksen tuloksiin, koska ruokinnat säilyivät samoina läpi kokeen.

Kokeen alkaessa vasikat olivat keskimäärin 17 viikon ikäisiä ja $139 \mathrm{~kg}$ painoisia. Kokeessa oli kaksi 20 vrk pituista jaksoa. Molempien jaksojen ensimmäisen 10 vrk aikana vasikoilla ei ollut käytössään karjaharjaa (EIKAR) ja jaksojen jälkimmäisen 10 vrk aikana vasikoilla oli käytössään karjaharja (KAR). Vasikoita videokuvattiin neljä kertaa 15 tunnin (klo 6:00-21:00) ajan. Videokuvaukset tehtiin jokaisen harjattoman ja harjallisen jakson viimeisen kolmen vuorokauden aikana. Samaan aikaan kuvattiin kahta karsinaa. Videonauhoilta kerättiin vasikoiden turkinhoitoon ja suun käyttöön liittyvät käyttäytymishavainnot jatkuvalla seurannalla etogrammin (Taulukko 1) mukaisesti. Turkinhoitohavaintojen yhteydessä kirjattiin ylös myös toiminnon kohde (pää/kaula, keskivartalo, jalat, häntä).

Muuttujien tilastollinen testaus tehtiin lineaarisella sekamallilla SPSS for Windows 14.0 ohjelmalla. Mallissa kiinteinä tekijöinä olivat käsittely (karjaharja, ei karjaharjaa), jakso (jakso 1, jakso 2) sekä näiden yhdysvaikutus. Satunnaistekijöinä olivat karsina ja eläin. Testattaessa muuttujia hankaa karjaharjaan, syrjäyttää karjaharjalta ja manipuloi karjaharjaa käsittelyn vaikutus jätettiin pois mallista. Malliin valittiin sopivin toistomittausten kovarianssirakenne (compound symmetry structure, heterogeneous compound symmetry structure) Akaiken informaatiokriteerin perusteella. Mallin oletusten voimassaolo tarkastettiin ja tarvittaessa muuttujalle tehtiin Box-Cox muuttujamuunnos (Box ja Cox 1964). Muuttujamuunnos tehtiin kaikille muille muuttujille paitsi muuttujille hankaa karjahar- 
jaan, sosiaalinen leikki ja leikki yhteensä. Tulokset esitetään mallin estimoimina keskiarvoina ja hajontaa kuvaamaan käytetään $95 \%$ luottamusväliä. Muuttujamuunnoksen avulla lasketuilla muuttujilla tulosten esittämisessä käytetään takaisinmuunnettuja arvoja. Mikäli mallin virhetermien normaalisuutta ja varianssien yhtä suuruutta ei saavutettu muuttujamuunnoksella, tulokset esitetään keskiarvoina ja hajontaa kuvaamaan käytetään keskihajontaa. Vasikoiden turkinhoitotoimintojen osuudet kaikesta turkinhoitokäyttäytymisestä esitetään kuvailevasti.

Taulukko 1. Käyttäytymisseurannoissa havainnoidut toiminnot ja niiden kuvaukset.

\begin{tabular}{|l|l|}
\hline Toiminto & Kuvaus \\
\hline Nuolee itseään & Vasikka koskettaa kielellään keskivartaloaan, jalkaansa tai häntäänsä. $^{\text {a }}$ \\
\hline Hankaa karjaharjaan & $\begin{array}{l}\text { Vasikka hankaa päätään/niskaansa, keskivartaloaan, jalkaansa tai häntäänsä karja- } \\
\text { harjaa vasten. }\end{array}$ \\
\hline Hankaa rakenteisiin & $\begin{array}{l}\text { Vasikka hankaa päätään/niskaansa, keskivartaloaan, jalkaansa tai häntäänsä karsi- } \\
\text { nan rakenteita vasten. }\end{array}$ \\
\hline Hankaa toista eläintä vasten & Vasikka hankaa päätään toista eläintä vasten. \\
\hline Hankaa yhteensä & Hankaamishavainnot yhteensä. \\
\hline Rapsuttaa sorkalla & Vasikka rapsuttaa sorkallaan mitä tahansa vartalonsa osaa. \\
\hline Hoitaa turkkia yhteensä & Turkinhoito (nuolee, hankaa, rapsuttaa itseään) yhteensä. \\
\hline Syrjäyttää karjaharjalta & Vasikka syrjäyttää toisen eläimen karjaharjalta päästäkseen itse käyttämään sitä. \\
\hline Manipuloi karjaharjaa & Vasikka manipuloi suullaan (puree, nuolee, maistelee) karjaharjaa. \\
\hline Sosiaalinen leikki & Vasikka puskee toista eläintä tai hyppää toisen eläimen selkään. \\
\hline Juoksuleikki & Vasikka kirmaa, pukittaa, hyppii tai loikkii yksin tai yhdessä toisen eläimen kanssa. \\
\hline Leikki yhteensä & Sosiaalinen leikki ja juoksuleikki yhteensä. \\
\hline Kielenpyöritys & $\begin{array}{l}\text { Vasikka rullaa kieltään suun ulko- tai sisäpuolella tai heiluttaa kieltään suupielestä } \\
\text { toiseen. }\end{array}$ \\
\hline
\end{tabular}

${ }^{\mathrm{a}}$ Ei sisällä lyhytkestoisia nuolaisuja.

\section{Tulokset ja tulosten tarkastelu}

Suurin osa vasikoiden turkinhoitoon käyttämästä ajasta oli itsensä nuolemista (77-90 \% ajasta, Kuva 1). Hankaamisen osuus turkinhoitoon käytetystä ajasta oli EIKAR-käsittelyllä $10 \%$ ja KARkäsittelyllä $23 \%$. Sorkalla rapsuttamista havaittiin hyvin vähän. Toimintojen osuudet turkinhoitoon käytetystä ajasta olivat EIKAR-käsittelyllä hyvin samankaltaiset kuin Weeks ym. (1995) raportoivat 20-28 viikon ikäisillä vasikoilla, joilla ei myöskään ollut karjaharjaa käytössään. Weeksin ym. (1995) kokeessa vasikoiden turkinhoitokäyttäytymisestä $87 \%$ oli itsensä nuolemista, $11 \%$ hankaamista ja 2 $\%$ sorkalla rapsuttamista.

Lähes kaikki lehmät ja vasikat hyödyntävät pyörivää karjaharjaa turkinhoidossa saadessaan mahdollisuuden sen käyttöön (Georg ja Totschek 2001, DeVries ym. 2007, Georg ym. 2007). Georgin ja Totschekin (2001) tutkimuksessa kaikki lehmät käyttivät pyörivää karjaharjaa viikon sisällä harjan asentamisesta. DeVries ym. (2007) raportoivat lehmistä 99 \% käyttävän pyörivää karjaharjaa kahden viikon sisällä harjan asentamisesta. Georg ym. (2007) havaitsivat vasikoista 98 \% käyttävän pyörivää karjaharjaa. Yhtä lailla kiinteä karjaharja osoittautui tutkimuksessamme suosituksi vasikoiden keskuudessa. Kaikkien vasikoiden havaittiin rapsuttavan itseään karjaharjaa vasten tarkkailujen aikana 7-9 päivän kuluttua karjaharjan kiinnittämisestä karsinaan. Vasikat myös nakersivat ja maistelivat karjaharjaa suullaan, mutta valtaosa ( $83 \%$ ) karjaharjan parissa vietetystä ajasta oli itsensä hankaamista.

Vasikat nuolivat keskivartaloaan ja jalkojaan sekä hankasivat itseään rakenteita ja karjaharjaa vasten enemmän jaksolla 2 kuin jaksolla 1 (Taulukko 2). Jaksolla 1 vasikat saivat elämänsä ensimmäisen kokemuksen karjaharjasta, kun taas jaksolla 2 karjaharja oli jo toista kertaa niiden käytössä. Kokeen toistomittauskoeasetelma sekä vasikoiden kasvu kokeen edetessä vaikeuttavat jaksolla 2 tapahtuneen turkinhoitokäyttäytymisen lisääntymisen syiden arviointia. Tutkimuksessa ei myöskään selvitetty vasikoiden yleistä aktiivisuutta, joka olisi voinut selittää eroja turkinhoitokäyttäytymisen määrässä jaksojen välillä. 
Karjaharjan kiinnittäminen karsinaan ei vaikuttanut vasikoiden turkinhoidon kokonaismäärään jaksolla $1(20 \mathrm{~min} / 15 \mathrm{~h})$ tai jaksolla $2(27 \mathrm{~min} / 15 \mathrm{~h})$, mutta eri turkinhoitotoimintojen suhteelliset osuudet muuttuivat, kun vasikat saivat karjaharjan käyttöönsä (Kuva 1, Taulukko 2). KAR-käsittelyllä vasikat nuolivat jalkojaan merkitsevästi vähemmän ja keskivartaloaan suuntaa antavasti vähemmän kuin EIKAR-käsittelyllä. Lisäksi rakenteita vasten hankaamista ja toista eläintä vasten hankaamista (vain jaksolla 2) havaittiin vähemmän KAR-käsittelyllä kuin EIKAR-käsittelyllä. Karjaharjaa käytettiin ahkerasti: KAR-käsittelyllä hankaamiseen kaikkiaan käytetty aika oli 2,7 kertaa niin suuri kuin EIKAR-käsittelyllä. Näyttää siltä, että KAR-käsittelyllä vasikat valitsivat hankaamisen kohteekseen mieluummin karjaharjan kuin karsinan muut rakenteet tai toisen eläimen.

Samaan tapaan kuin omassa kokeessamme DeVries ym. (2007) havaitsivat lehmien vähentävän rakenteisiin hankaamista, kun eläimet saivat käyttöönsä pyörivän karjaharjan. Kaikkiaan DeVriesin ym. (2007) kokeessa hankaamista havaittiin karjaharjan kiinnittämisen jälkeen kuusi kertaa niin paljon kuin ennen karjaharjan kiinnittämistä. Kohari ym. (2007) selvittivät puustoisen laitumen vaikutusta lehmien turkinhoitokäyttäytymiseen. Päinvastoin kuin omassa kokeessamme Koharin ym. (2007) tutkimuksessa itsensä nuolemisen ja rakenteisiin hankaamisen määrät eivät muuttuneet eläinten saadessa käyttöönsä hankaamiseen soveltuvia kohteita (puita). Kaikkiaan lehmillä havaittiin hankaamista puustoisella laitumella kaksikymmentä kertaa niin paljon kuin puuttomalla laitumella.

Etenkin ahtaissa yksilökarsinoissa pidetyillä vasikoilla tavattava epänormaalin käyttäytymisen muoto on liiallinen itsensä nuoleminen (Fraser ja Broom 2002). Vasikat nuolevat itseään pitkiä aikoja kehon osista, joihin ylettävät. Vasikoiden pötseistä on löydetty niellyistä karvoista muodostuneita suuriakin karvapalloja, jotka ovat terveydelle vaarallisia. Itsensä nuolemisessa voi myös näkyä stereotyyppisen käyttäytymisen piirteitä. Kerrin ja Wood-Gushin (1987) mukaan suuri turkinhoitokäyttäytymisen määrä vasikoilla voi olla konfliktikäyttäytymistä. Krohn (1994) puolestaan on esittänyt, että parressa pidetyillä lehmillä suuri määrä lyhyissä jaksoissa esiintyvää turkinhoitoa voi olla sijaiskäyttäytymistä.

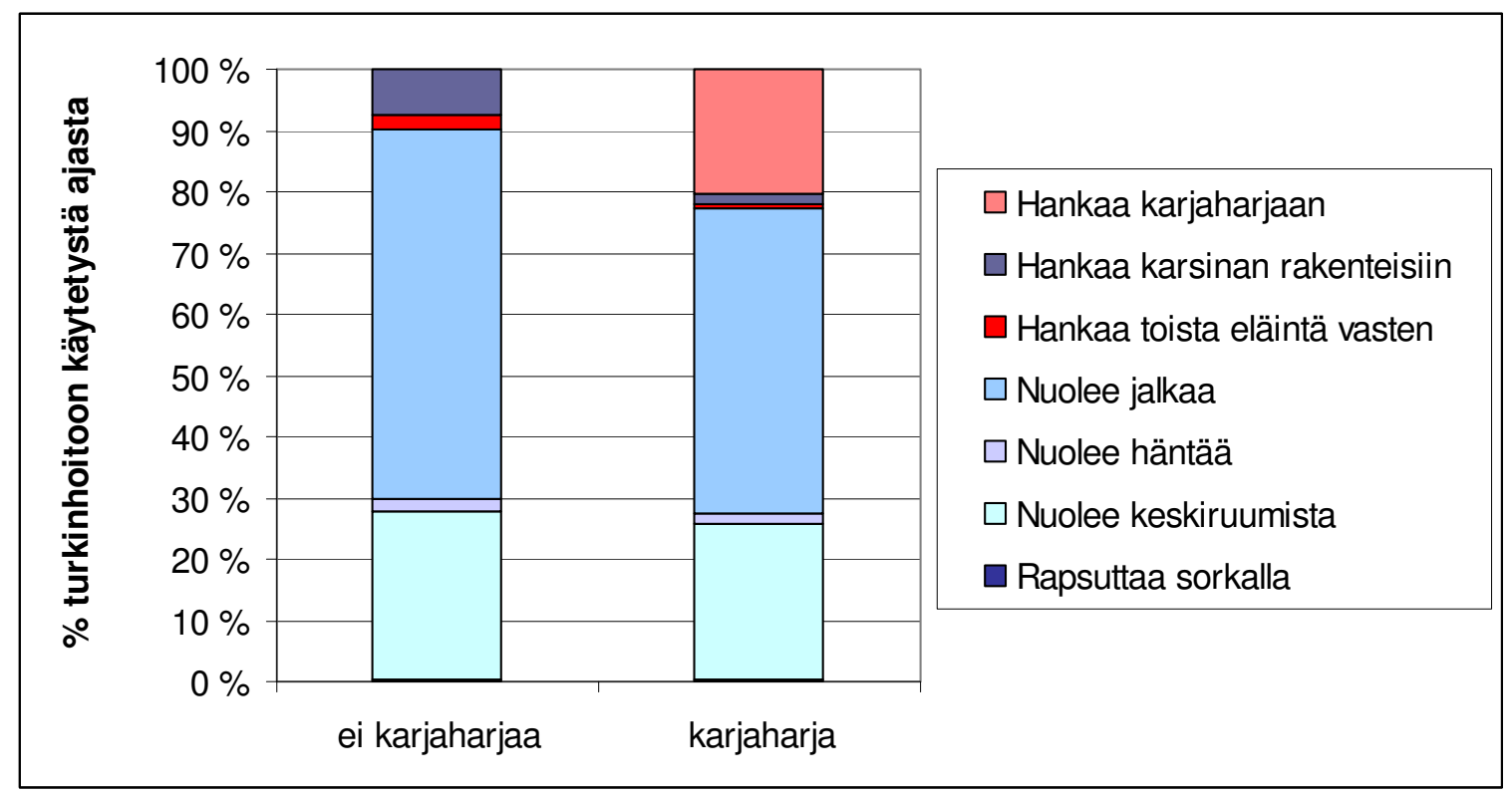

Kuva 1. Vasikoiden turkinhoitokäyttäytymisen jakautuminen eri toimintoihin, kun vasikoilla ei ollut käytössään karjaharjaa ja kun vasikoilla oli käytössään karjaharja. 
Taulukko 2. Vasikoiden eri toimintoihin käyttämä aika tai toiminnon lukumäärä klo 6:00-21:00 välisenä aikana (keskiarvo ja 95 \% luottamusväli).

\begin{tabular}{|c|c|c|c|c|c|c|c|}
\hline & \multicolumn{2}{|c|}{ Käsittely (K) } & \multicolumn{2}{|c|}{ Jakso (J) } & \multicolumn{3}{|c|}{ Tilastollinen merkitsevyys } \\
\hline & Ei karjaharjaa & Karjaharja & 1 & 2 & $\mathrm{~K}$ & $\mathrm{~J}$ & $\mathrm{~K} \times \mathrm{J}$ \\
\hline \multicolumn{8}{|l|}{ Turkinhoito } \\
\hline Nuolee keskivartaloa, min & $6,6(5,6,7,8)$ & $5,7(4,8,6,8)$ & $5,6(4,6,6,6)$ & $6,8(5,7,8,1)$ & 0,068 & 0,034 & 0,912 \\
\hline Nuolee häntää, min & $0,12(0,04,0,27)$ & $0,10(0,03,0,22)$ & $0,08(0,02,0,20)$ & $0,15(0,05,0,34)$ & 0,610 & 0,319 & 0,561 \\
\hline Hankaa karjaharjaan, min & & & $4,2(2,1,6,3)^{\mathrm{a}}$ & $6,0(3,8,8,1)^{\mathrm{a}}$ & - & 0,040 & - \\
\hline Hankaa rakenteisiin, min & $1,3(0,8,1,9)$ & $0,2(0,1,0,4)$ & $0,3(0,1,0,6)$ & $1,0(0,6,1,5)$ & $<0,001$ & $<0,001$ & 0,323 \\
\hline Hankaa yhteensä, min & $1,9(1,2,2,9)$ & $5,1(3,7,6,8)$ & $2,5(1,6,3,7)$ & $4,2(3,0,5,7)$ & $<0,001$ & 0,001 & 0,414 \\
\hline Rapsuttaa itseään sorkalla, min & $0,06 \pm 0,11^{b}$ & $0,06 \pm 0,09^{b}$ & $0,03 \pm 0,06^{b}$ & $0,09 \pm 0,12^{b}$ & - & - & - \\
\hline Hoitaa turkkia yhteensä, min & $23,7(19,8,28,2)$ & $23,2(19,4,27,6)$ & $20,3(17,0,24,3)$ & $26,9(22,6,32,0)$ & 0,749 & $<0,001$ & 0,481 \\
\hline \multicolumn{8}{|l|}{ Muu toiminto } \\
\hline Syrjäyttää karjaharjalta, frekvenssi & & & $0,2 \pm 0,5^{\mathrm{ab}}$ & $0,2 \pm 0,4^{\mathrm{ab}}$ & - & - & - \\
\hline Manipuloi karjaharjaa, min & & & $0,7(0,3,1,5)^{\mathrm{a}}$ & $1,3(0,6,2,6)^{\mathrm{a}}$ & - & 0,039 & - \\
\hline
\end{tabular}

${ }^{\mathrm{a}}$ KAR-käsittelyllä, ${ }^{\mathrm{b}}$ Keskiarvo \pm keskihajonta, - Ei testattu. 
Tutkimuksessamme vasikat vähensivät etenkin jalkoihin kohdistuvaa nuolemista saadessaan karjaharjan käyttöönsä. Tämä voi merkitä sitä, että osa itsensä nuolemisesta oli epänormaalia, esimerkiksi kasvatusympäristön yksitoikkoisuudesta johtuvaa. Karjaharja saattoi siten vaikuttaa vasikoiden hyvinvointiin edullisesti tarjoamalla vasikoille mielekästä puuhaa ja kohdistamalla eläinten mielenkiintoa itsensä nuolemisesta karjaharjaan rapsutteluun. Karjaharjalla ei kokeessamme havaittu vaikutusta vasikoiden stereotyyppisen kielenpyörityksen tai leikkikäyttäytymisen määrään. Stereotyyppistä kielenpyöritystä havaittiin kuitenkin yleisesti, mikä viittaa siihen, että vasikoilla oli vaikeuksia sopeutua kasvatusympäristöönsä.

Kokeessamme vasikat käyttivät turkinhoitoon (nuolee itseään, hankaa ja rapsuttaa sorkalla) keskimäärin 23,5 minuuttia päiväaikaan (klo 6:00-21:00), mikä on huomattavasti enemmän kuin lehmillä on raportoitu (Krohn 1994, Munksgaard ja Simonsen 1996). Munksgaardin ja Simonsenin (1996) kokeessa lehmät hankasivat ja nuolivat itseään yhteensä viiden minuutin ajan vuorokaudessa. Lehmät olivat parressa, mikä saattoi rajoittaa niiden luonnollista turkinhoitokäyttäytymistä. Krohnin (1994) kokeessa lehmillä havaittiin hankaamista ja itsensä nuolemista 6,2 minuuttia päiväaikaan (klo 6:0021:00). Näillä pihatossa pidetyillä lehmillä oli halutessaan pääsy laitumelle. Kokeessamme vasikat käyttivät aikaa lähes yhtä paljon karjaharjaan hankaamiseen (5,1 min) päiväaikaan (klo 6:00-21:00) kuin lehmät käyttivät aikaa pyörivän karjaharja käyttöön (6,8 min) koko vuorokauden aikana (DeVries ym. 2007).

DeVries ym. (2007) tutkimuksessa lehmät vähensivät päähän kohdistuvia hankaamiskertoja ja lisäsivät niskaan, selkään ja häntään kohdistuvia hankaamiskertoja, kun eläimille annettiin käyttöön pyörivä karjaharja. DeVries ym. (2007) päättelivät, että pyörivä karjaharja helpottaa lehmien turkinhoitoa ja etenkin ylettymistä hankalasti tavoitettaville kehon alueille. Omassa kokeessamme ei erotettu kohdistuiko hankaaminen päähän vai niskaan. Selkään tai häntään kohdistuvan hankaamisen lisääntymistä ei kokeessamme juuri havaittu: hankaamisesta päähän tai kaulaan kohdistui 100,0 \% EIKARkäsittelyllä ja 99,4 \% KAR-käsittelyllä. Tulos selittynee sillä, että kokeessamme käytimme vain yhtä pystysuoraan seinään kiinnitettyä $50 \times 10 \mathrm{~cm}$ harjaosaa.

Vasikat syrjäyttivät toisiaan karjaharjalta vain keskimäärin 0,2 kertaa/vasikka 15 tunnin tarkkailun aikana. Lehmillä tehtyjen havaintojen mukaan ruokintapöydällä tapahtuviin syrjäytyksiin $(18,9$ syrjäytystä/lehmä/vrk) verrattuna pyörivältä karjaharjalta syrjäyttäminen $(0,5$ syrjäytystä/lehmä/vrk) on vähäistä (Val-Laillet ym. 2008). Val-Lailletin ym. (2008) tutkimuksissa 12 lehmällä oli käytössään 1 karjaharja. Voidaan olettaa, että myös vasikoilla ravinto on resurssi, johon kohdistuu eniten kilpailua. Resurssiin kohdistuvan kilpailun määrään vaikuttaa myös sitä hyödyntävien eläinten määrä. Tutkimuksessamme viisi vasikkaa käytti yhtä karjaharjaa sopuisasti, mutta mikäli eläinmäärä kasvaisi, karjaharjaan kohdistuvan kilpailun voisi jossain vaiheessa olettaa lisääntyvän.

\section{Johtopäätökset}

Kaikki tutkimuksen vasikat (ikä 17-23 viikkoa) hyödynsivät kiinteää karjaharjaa hankaamiseen. Kiinteällä karjaharjalla ei ollut vaikutusta vasikoiden turkin hoitoon kokonaisuudessaan käyttämään aikaan. Saadessaan karjaharjan käyttöönsä vasikat kuitenkin nuolivat erityisesti jalkojaan vähemmän ja vastaavasti hankasivat itseään enemmän. Itsensä nuolemisen vähentyminen voi merkitä vasikoiden hyvinvoinnin parantumista, koska jatkuvaa ja usein toistuvaa itsensä nuolemista pidetään epänormaalina käyttäytymisenä. Karjaharjaan kohdistuva kilpailu oli hyvin vähäistä, kun yhtä karjaharjaa käytti viisi vasikkaa. Tutkimuksen perusteella kiinteää karjaharjaa, jonka etuna on myös edullisuus, voidaan suositella vasikoille.

\section{Kiitokset}

Kiitämme MTT Ruukin navetan henkilökuntaa, erityisesti Outi Ukkolaa, hyvästä eläinten hoidosta ja sujuvasti toteutetusta vasikoiden videoinnista, Satu Raussia osallistumisesta koeasetelman suunnitteluun, Maarit Hyrkästä avusta aineiston tilastollisessa testauksessa sekä FinnLacto Oy:tä karjaharjojen lahjoittamisesta tutkimuksen käyttöön.

\section{Kirjallisuus}

Box, G.E.P. \& Cox, D.R. 1964. An analysis of transformations. J. Roy. Statist. Soc. Ser. B 26, 211-252.

DeVries, T.J. Vankova, M. Veira, D.M. \& Keyserlingk, M.A.G. von 2007. Usage of mechanical brushes by lactating dairy cows. J. Dairy Sci. 90: 2241-2245. 
Fraser A.F \& Broom. D.M. 2002. Farm animal behaviour and welfare. Kolmas painos. CAB International: Wallingford. $437 \mathrm{~s}$.

Georg, H. \& Totschek, K. 2001. Untersuchung einer automatischen Kuhputzmaschine fur Milchkuhe. Landtechnik 56: 260-261.

Georg, H., Jahn-Falk, D. \& Ude, G. 2007. Technik gegen Langeweile - Wie wird eine automatische Putzmaschine von Kalbern angenommen? Landtechnik 62: 166-167.

Kerr, S.G.C. \& Wood-Gush, D.G.M. 1987. A comparison of the early behaviour of intensively and extensively reared calves. Anim. Prod. 45: 181-190.

Kohari, D., Kosako, T., Fukasawa, M. \& Tsukada, H. 2007. Effect of environmental enrichment by providing trees as rubbing objects in grassland: grazing cattle need tree-grooming. Anim. Sci. J. 78: 413-416.

Krohn, C.C. 1994. Behaviour of dairy cows kept in extensive (loose housing/pasture) or intensive (tie stall) environments. III. Grooming, exploration and abnormal behaviour. Appl. Anim. Behav. Sci. 42: 73-86.

Munksgaard, L. \& Simonsen, H.B. 1996. Behavioral and pituitary adrenal-axis responses of dairy cows to social isolation and deprivation of lying down. J. Anim. Sci. 74: 769-778.

Ninomiya, S. \& Sato, S. 2009. Effects of 'Five freedoms' environmental enrichment on the welfare of calves reared indoors. Anim. Sci. J. 80: 347-351.

Simonsen, H.B. 1979. Grooming behaviour of domestic cattle. Nordisk Veterinaermedicin 31: 1-5.

Val-Laillet, D., Veira, D.M. \& Keyserlingk, M.A.G. von 2008. Dominance in free-stall-housed dairy cattle is dependent upon resource. J. Dairy Sci. 91: 3922-3926.

Weeks, C.A., Nicol, C.J. \& Titchener, R.N. 1995. Effects of the sucking louse (Linognathus vituli) on the grooming behaviour of housed calves. Vet. Rec. 137: 33-35 